\title{
Quando a Educação Ambiental Anuncia a Ecologia Política: o que dizem os anais do Encontro Pesquisa em Educação Ambiental?
}

\section{When Environmental Education announces Political Ecology: what do the annals of the Environmental Education Research Meeting say?}

\section{Cuando la Educación Ambiental anuncia la Ecologia Política: ¿qué dicen los anales del Encuentro de Investigación en Educación Ambiental?}

\author{
Michele Alice da Silva ${ }^{1}$ \\ Camila Neves Silva ${ }^{2}$ \\ Angélica Cosenza ${ }^{3}$ \\ Olga Alicia Gallardo Milanés ${ }^{4}$
}

\begin{abstract}
Resumo
O presente trabalho tem como objetivo discutir como vem sendo pensada a pesquisa em Educação Ambiental no Brasil, em sua relação com o campo da Ecologia Política - EP. Para tanto, foi feito um levantamento de trabalhos que fazem referência ao termo Ecologia Política, no título, no resumo e/ou nas palavras-chave, nos anais dos Encontros Pesquisa em Educação Ambiental - EPEA, em suas dez edições. Os resultados retratam uma tendência de crescimento do número de trabalhos que abordam a Educação Ambiental em diálogo com o campo da Ecologia Política, ainda que possamos considerar o limite deste trabalho ao, por exemplo, não incluir estudos que fazem referência à EP no corpo do texto, ou ainda outros periódicos e eventos. $\mathrm{O}$ aumento no número de trabalhos que correlacionam ambos os campos pode estar vinculado a uma tendência do plural campo da Educação Ambiental em abordar preocupações que, também, são centrais à Ecologia Política, como a compreensão dos conflitos ambientais e de suas possibilidades educativas.
\end{abstract}

Palavras-chave: Ecologia Política. Educação Ambiental. Conflitos ambientais.

\begin{abstract}
This paper aims to discuss how Environmental Education has considered, in Brazil, in its relationship with the field of Political Ecology - PE. With this aim, we made a survey of articles that refer, in the title, abstract and/or keywords, to the term Political Ecology in the annals of the Environmental Education Research Meeting - EPEA, in its ten editions. The results show a growing trend in the number of works that address Environmental Education in dialogue with the field of Political Ecology, although we may consider the limit of this work by, for example, not including studies that refer to PE in the body of the text, or other periodicals and events. The increase in the number of works that correlate both fields may be linked to a trend in the plural field of
\end{abstract}

\footnotetext{
${ }^{1}$ Mestre em Educação (PPGE/ UFJF). Professora de Educação Básica (SEE/MG). Doutoranda em Educação (PPGE/UFJF). E-mail: micheleasbio@gmail.com

${ }^{2}$ Mestre em Ecologia PGECOL/UFJF. Professora Assistente 2 Departamento de Geociências (ICH/UFJF). Doutoranda em Educação (PPGE/UFJF).

${ }^{3}$ Doutora em Educação em Ciências e Saúde (NUTES/UFRJ). Professora da Faculdade de Educação da Universidade Federal de Juiz de Fora e do Programa de Pós-Graduação em Educação (PPGE/ FACED/ UFJF). Pesquisadora no Grupo de Pesquisa "Núcleo de Educação em Ciência, Matemática e Tecnologia" (NEC/UFJF), onde coordena o GEA- Grupo de estudos e pesquisas em educação ambiental GEA/UFJF). Coordenadora das Licenciaturas (PROGRAD/UFJF) e Coordenadora Institucional do Programa Institucional de Bolsa de Iniciação à Docência (PIBID/UFJF).

${ }^{4}$ Pós-doutorado em Sociedade e Desenvolvimento (PPGSED/ UNESPAR). Professora visitante do Programa de Pós-Graduação em Educação da Faculdade de Educação da Universidade Federal de Juiz de Fora (PPGE/ FACED/ UFJF).
} 
Environmental Education when it addresses concerns that are also central to Political Ecology, such as the understanding of environmental conflicts and their educational possibilities.

Keywords: Political Ecology. Environmental Education. Environmental Conflicts.

\section{Resumen}

Este trabajo tiene como objetivo comprender cómo está siendo pensada la investigación en Educación Ambiental en Brasil, en su relación con el campo de la Ecología Política - EP. Con este fin, se realizó un levantamiento de trabajos que hacen referencia al término Ecología política, en el título, resumen y/o palabras clave, en los anales de los Encuentros de Investigación en Educación Ambiental - EPEA, en sus diez ediciones. Los resultados muestran una tendencia de crecimiento en el número de trabajos que abordan la Educación Ambiental en diálogo con el campo de la Ecología Política, aunque los referidos trabajos tienen limitaciones como, por ejemplo, no incluyen estudios que hacen referencia a la EP en el cuerpo del texto, o en otros periódicos y eventos. El aumento en el número de trabajos que correlacionan ambos campos, puede estar vinculado a una tendencia plural en el campo de la Educación Ambiental, al abordar preocupaciones que también son centrales en la Ecología Política, como la compresión de los conflictos ambientales y de sus posibilidades educativas.

Palabras clave: Ecología Política. Educación ambiental. Conflictos Ambientales.

\section{Introdução}

Enquanto vivenciamos um complexo quadro de processos ambientais globais, devido às alterações climáticas e ao avanço diário de uma pandemia com impactos sociais e econômicos assustadores, estudiosos/as dos mais diversos campos do conhecimento têm se dedicado a compreender como as múltiplas relações estabelecidas entre as sociedades humanas e o ambiente influenciam em tais processos, e como estes são experienciados por diferentes grupos sociais, de formas desiguais (PALACIO; VARGAS; HENNESSY, 2017; DAVIS, 2020; SANTOS, 2020).

A pandemia da Covid 19, causada pelo novo Coronavírus, SARS-CoV2, vem expondo desigualdades sociais, em vários dos países afetados, já que, segundo Bihr (2020), o estado saudável (ou não) do corpo físico de um indivíduo depende, principalmente, do estado saudável (ou não) do corpo social do qual faz parte. Nesse contexto, devido à notável diferença à exposição aos riscos, a atual pandemia, para Harvey (2020), revela que suas consequências têm classe, gênero e raça. Se, por um lado, algumas pessoas podem se isolar, trabalhar em casa, seguir as normas de higiene e cuidado, por outro, existem aquelas que estão à mercê das demissões, dos despojos, da falta de saneamento básico, de violência doméstica. Todo o efeito dominó que a pandemia tem gerado sobre a economia global tem mostrado o quão socioambientalmente insustentável é a globalização capitalista, e o quanto o quadro de desigualdades se relaciona com as posições políticas estabelecidas pelos governos, por estarem os impactos causados pela propagação do vírus altamente relacionados às vulnerabilidades socioambientais decorrentes do modelo hegemônico. Enquanto alguns governantes adotam medidas que contemplam diferentes setores da sociedade, outros insistem em dar uma assistência maior a setores já privilegiados, como o setor financeiro (DAVIS, 2020; HARVEY, 2020; SANTOS, 2020).

Dessa maneira, tomamos o caso da pandemia, na conjuntura atual, por acreditar que ela nos ajuda a compreender a crise ambiental contemporânea, ao deixar em evidência suas causas e consequências, como a exposição desigual aos riscos e danos socioambientais, e nos colocar no movimento de pensar as relações que são estabelecidas entre as sociedades, e destas com a natureza, em decorrência dos sentidos que são atribuídos à sociedade e ao ambiente, por meio do que Santos (2020) anuncia como a "pedagogia do vírus". Tais apreensões ficam evidentes no Manifesto de Educadores Ambientais do Observare - 
Observatório da Educação Ambiental, ao conceberem que "a saúde pública e o bem-viver estão intrinsecamente ligados a eficazes políticas educacionais e de cuidado ambiental. (...) $\mathrm{O}$ meio ambiente é um sistema que exige cuidados, pois sua degradação fragiliza integralmente este complexo planeta" (OBSERVARE, 2020, [s.p.]). Criado em 2019, esse coletivo reúne ambientalistas e educadores/as de todo Brasil, focados/as na possibilidade de produção de diálogos, manifestos, atos e táticas que possam fortalecer a educação ambiental (EA) no país.

Nesse cenário, estudiosos/as do campo socioambiental reafirmam, há décadas, que as causas do caos que estamos vivenciando estão estreitamente relacionadas com o modelo de sociedade hegemônico. Em consequência, a crise ambiental se insere em um panorama mais amplo, uma crise civilizatória, no qual as relações sociais se estabelecem, de forma desigual e fragmentada, nas diferentes sociedades humanas, determinando grupos e classes sociais (FOLADORI, 1999; LEFEBVRE, 1999; LEFF, 2009; SANTOS; MENEZES, 2009). Nesse sentido, de forma a se contrapor os discursos hegemônicos que buscam anunciar a pobreza, a superpopulação e a poluição como as principais causas da crise ambiental, Foladori (2018) reflete sobre as implicações do capitalismo ao ambiente, salientando como os instrumentos utilizados pelo sistema hegemônico potencializam uma racionalidade que separa o ser humano e a natureza.

\footnotetext{
Esta mediación obliga a un metabolismo muy diferente al resto de los seres vivos; porque en el caso de la sociedad humana el metabolismo depende y se ajusta a la distribución en clases sociales. La apropiación diferencial y clasista de los medios de producción conduce al también desigual metabolismo de las clases con la naturaleza externa. Toda acción sobre la naturaleza externa es, también, una transformación al interior de la propia sociedad humana (FOLADORI, 2018, p. 165).
}

Nessa busca por compreender a estreita relação entre as questões ambientais e o modo de organização das sociedades, o campo da Ecologia Política (EP) emerge. Um campo de investigação teórico e de ação política, que se coloca a analisar e a enfrentar questões ambientais latentes do século XXI, apresentando novas perguntas e desafios teórico-práticos (LEFF, 2013). Com características muito próprias, embora tenha um desenvolvimento diverso e ramificado, tal campo tem concentrado seus olhares no contexto da América Latina, evidenciando uma racionalidade que emerge dos modos de ser, dos processos de luta, dos povos afro, ameríndios, subalternizados, e incorpora as dimensões social, cultural e histórica às discussões sobre o ambiente e a sociedade (ALIMONDA, 2017).

Desse modo, a Ecologia Política traz nova perspectiva para a abordagem das questões ambientais. Por meio de encontros entre a tradição do pensamento crítico latino-americano e as experiências e estratégias de seus povos, propõe um giro ecopolítico, admitindo perspectivas do socioambientalismo, como a luta por justiça ambiental (ALIMONDA, 2015; MARTÍNEZ-ALIER, 2015). Tal campo nos convida a deslocarmos nossos olhares para outras epistemologias, anunciando teorias e práticas que possibilitem uma decolonização do saber, e façam emergir insurgências e lutas decoloniais, diante do atual sistema mundo hegemônico, que potencializa assimetrias e desigualdades socioambientais (SANTOS 2006; LEFF, 2018;). Segundo Santos (2006), é preciso legitimar outros saberes, outros modos de compreensão da realidade, da natureza, das relações sociais, que são apreendidos desde o Sul (o qual não se limita a um sul geográfico), conforme ressalta Porto-Gonçalves:

[...] temos uma ordem geopolítica que, em suas diversas escalas, se vê atravessada pelo colonialismo, ou melhor, pela colonialidade do poder, para usar a expressão sugerida por Anibal Quijano (2000), e pela colonialidade do saber, conforme Edgardo Lander (2000), que se sustenta na dominação de classe, étnico-racial, patriarcal e da natureza. Foram, sobretudo, os varões, burgueses e gestores, brancos 
e criollos que protagonizaram a instituição dessa ordem mundial (PORTOGONÇALVES, 2016, p. 12).

A colonialidade do saber e do poder se constitui a partir do estabelecimento da lógica moderno-colonial, decorrente de um legado epistemológico eurocentrista, que aniquila qualquer outra forma de pensar e conceber o mundo, como as epistemes e modos de produção que emergem nos povos ameríndios e africanos. E, nesse contexto, as noções de exclusão do outro, como a concepção de raças e a negação de culturas, se manifestam, estruturando as relações de poder.

Partindo dessa compreensão, Quijano (2000) adverte que o fim do colonialismo não significa o fim da colonialidade, por esta ser constitutiva da modernidade. Portanto, a Ecologia Política propõe o estabelecimento de uma lógica decolonial, a qual parte de um movimento de resistência frente à lógica da modernidade/colonialidade (QUIJANO, 2005).

Assim, ao reconhecer a luta ambiental como pelo bem comum e pela justiça social, tal campo assume, como lugares de enunciação, a dúvida e a busca pela nossa identidade; a realidade geo-histórica em comum da América Latina; a desconfiança em relação às racionalidades convencionais, positivistas; e uma posição fronteiriça em relação aos sistemas de conhecimento estabelecidos hegemonicamente, por conceber o conhecimento como forma de regulação (ALIMONDA, 2017).

Nesse sentido, Walsh (2017), ao discutir o sistema hegemônico, com seu projeto capitalista-modernizador-extrativista, que provoca destruição e expropriação da natureza, e sua lógica patriarcal-paterna-colonial, que reprime, silencia, criminaliza e violenta sujeitos e saberes, se coloca a anunciar e a compreender as pedagogias (processos, projetos e práticas) insurgentes que brotam em meio às rachaduras do sistema hegemônico, sistema de guerramorte mundial, que deriva de "um paradigma de guerra", por estabelecer "una confrontación directa con las jerarquías de raza, género y sexualidad, que fueron creadas o fortalecidas por la modernidad europea, en el proceso de conquista y esclavización de un sin número de pueblos en el planeta" (MALDONADO-TORRES, 2007, p. 161). Pedagogias essas que potencializam a compreensão da realidade, a partir de um pensamento reflexivo e crítico, bem como contribuem para o enfrentamento das assimetrias e desigualdades socioambientais.

Ao encontro dessa perspectiva, e no que se relaciona à educação, Loureiro e Layrargues (2013) discutem a consolidação da Educação Ambiental (EA), na última década, como um campo social, em função de um movimento histórico protagonizado por agentes de diferentes setores da sociedade, os quais estabelecem discursos e práticas distintas sobre a questão ambiental. Contrapondo-se a uma perspectiva reducionista que limita as preocupações ambientais a aspectos naturais ou instrumentais, o campo da EA vem assumindo uma perspectiva crítica que parte de aspectos sociais e paradigmas historicamente construídos sobre o ambiente, tecendo aproximações entre o sujeito ambiental e o fazer política, e provocando deslocamentos do individual para o coletivo.

Dessa maneira, os/as pesquisadores/as do campo, comprometidos/as com uma perspectiva crítica têm assumido a defesa de uma EA que se configura como instrumento de resposta e enfrentamento à crise civilizatória. Com isso, buscam denunciar as mazelas decorrentes do sistema hegemônico, atentando-se para os gritos dos/as excluídos/as e dos/as atingidos/as, e para as pedagogias que emergem em meio aos enfrentamentos e aos modos de produção de resistência e re-existência.

Para Loureiro e Layrargues (2013), as aproximações entre a EA e a EP se asseguram no fato de ambos os campos buscarem "um processo argumentativo contínuo de ressignificação ideológica da questão ambiental, agindo em contraponto às interpretações hegemônicas do senso comum acerca do fenômeno socioambiental" (LOUREIRO; LAYRARGUES, 2013, p. 68). Ao assumirem a luta ambiental como luta pelo bem comum, 
os campos da EA Crítica e da EP direcionam olhares para outras racionalidades, as quais compreendem o conflito, o risco e a vulnerabilidade ambiental como categorias de análise sobre a conjuntura social contemporânea que, à luz da educação, potencializam reflexões pedagógicas, uma vez que revelam sujeitos com diferentes concepções de mundo a partir da questão ambiental (KASSIADOU; SÁNCHEZ, 2019, p. 11).

Desse modo, por meio de diálogos entre estudiosos/as do campo da EP, como Aníbal Quijano, Boaventura de Sousa Santos, Catherine Walsh e Enrique Leff, o objetivo deste trabalho é compreender como vem sendo pensada a pesquisa em Educação Ambiental no Brasil, em sua relação com o campo da Ecologia Política. Sob quais pressupostos se estabelece essa relação teórica e quais contribuições a EP lança à EA?

Tal relação será problematizada, aqui, a partir do corpus obtido nos anais do Encontro Pesquisa em Educação Ambiental - EPEA - ao longo de suas dez edições. O EPEA surgiu em 2001, com o objetivo de socializar os conhecimentos produzidos por pesquisas no campo da EA, constituindo-se em um dos principais espaços acadêmicos para discussão, reflexão e sistematização das produções científicas em educação ambiental.

\section{Aspectos Metodológicos}

De forma a compreender as aproximações teóricas entre os campos da Ecologia Política e da Educação Ambiental, optamos pela abordagem qualitativa, utilizando a Análise de Conteúdo (BARDIN, 2011).

De acordo com o método proposto por Bardin (2011, p. 37) "a análise de conteúdo é um conjunto de técnicas de análise das comunicações", em que a descrição analítica se estabelece a partir de procedimentos sistemáticos e objetivos de descrição do conteúdo das mensagens. No entanto, segundo a autora, tal análise não se limita ao conteúdo, podendo ser uma análise dos significados (análise temática), como, também, uma análise dos significantes (análise lexical, análise dos procedimentos). Nesse sentido, é necessário que se estabeleça a finalidade da análise, uma vez que sua intenção é "a inferência de conhecimentos relativos às condições de produção (ou, eventualmente, de recepção), inferência esta que recorre a indicadores (quantitativos ou não)" (BARDIN, 2011, p. 44).

Conforme o método proposto, a análise temática pode ser compreendida em três momentos: $1^{\circ}$ ) organização da análise, momento em que são expostas as ideias, estabelecendo-se os objetivos, meios e procedimentos que serão utilizados para análise; $2^{\circ}$ ) a codificação, que consiste em um processo de sistematização dos dados, com base nas suas características; e $3^{\circ}$ ) categorização, na qual é feita uma classificação dos elementos por diferenciação, instituindo grupos, com base em determinados critérios.

Dessa maneira, estabelecemos o EPEA para busca de trabalhos, em função da sua importância e representatividade no campo da pesquisa brasileira em EA. Nos debruçamos sobre a realização de um levantamento geral, filtrando os trabalhos que apresentavam o termo Ecologia Política, nos campos de busca: título, resumo e/ou palavras-chave. Acreditamos que a presença do termo em algum desses campos (ou concomitante) indica maior pertencimento da relação EA-EP, apesar de reconhecermos haver estudos que versem sobre a mesma, ainda que não a tragam nos campos de busca mencionados.

A análise foi feita em todos os trabalhos publicados e disponíveis nos anais online (898 trabalhos), no site oficial do EPEA, ao longo de suas dez edições (2001-2019). Os trabalhos filtrados foram lidos na íntegra, em busca de compreender os significados atribuídos à Ecologia Política na pesquisa em Educação Ambiental, seus lugares de enunciação, pressupostos e contribuições à EA.

Por fim, partindo de um denso processo de leitura e entrecruzamento de oito trabalhos selecionados e considerados relevantes à análise, procedemos à produção de categorias. Tal 
análise foi marcada por um movimento interpretativo, interessado em contribuir com a produção teórica sobre o modo com que os trabalhos filtrados denotam sentidos ao campo da EA a partir das contribuições da Ecologia Política.

\section{A Ecologia Política na literatura sobre Educação Ambiental}

Partindo de um total de 898 trabalhos publicados nos anais do EPEA, nas dez edições, encontramos oito com o uso da palavra Ecologia Política, filtrados nos campos de busca já mencionados. A Tabela 1 abaixo apresenta a frequência de trabalhos a cada edição do EPEA.

Tabela 1 - Distribuição dos trabalhos filtrados que fazem referência ao termo Ecologia Política em anais do EPEA, de 2001 a 2019

\begin{tabular}{l|c|c|c}
\hline Ano & Número de trabalhos & $\begin{array}{c}\text { Número de trabalhos com o } \\
\text { termo Ecologia Política }\end{array}$ & Frequência \\
\hline 2001 & 79 & - & - \\
\hline 2003 & 72 & - & - \\
\hline 2005 & 73 & - & - \\
\hline 2007 & 87 & - & - \\
\hline 2009 & 90 & - & $1,13 \%$ \\
\hline 2011 & 88 & 1 & $1,1 \%$ \\
\hline 2013 & 90 & 1 & $2,85 \%$ \\
\hline 2015 & 108 & 2 & $1,06 \%$ \\
\hline 2017 & 117 & 3 & $0,89 \%$ \\
\hline 2019 & 94 & 1 &
\end{tabular}

A partir dos números acima, embora haja um pequeno crescimento até o ano de 2017, é possível notar baixa frequência no número de trabalhos que potencializam a relação EA - EP ao longo dos anos, levando em conta o mecanismo de busca e o corpus por ele gerado. Esse resultado pode estar relacionado com a delimitação do corpus desta pesquisa, que considerou somente os trabalhos com menção direta do termo nos campos resumo, título e palavraschave. Entretanto, pode revelar certa tendência no plural campo da EA em incorporar temáticas que, também, são de interesse do campo da EP, como perspectivas de Justiça Ambiental e de Conflito Ambiental, tendo em vista que, conforme levantamento feito por Silva, Cosenza e Pinto (2017), as mesmas aparecem de forma incipiente nas discussões e nos trabalhos do EPEA. Tais autores reconhecem certa fragilidade, nos trabalhos, quando se trata de problematizar processos de desigualdades socioambientais, bem como uma invisibilização dos conflitos ambientais e dos sujeitos deles constitutivos. Semelhante levantamento também pode ser visto em Angeli (2017), ao caracterizar o contexto de produção das teses e dissertações em Educação Ambiental que problematizam o conceito de Justiça Ambiental, em um corpus documental de somente 23 trabalhos, sendo dezoito dissertações de mestrado e cinco teses de doutorado, concluídas no Brasil no período de 1981 a 2014. Aqui, ressaltamos a necessidade de novos levantamentos de área para compreender a interface entre EA e EP, o que ajuda a pensar o grande campo da EA na relação com outros campos e aportes.

Após leitura na íntegra dos oito trabalhos filtrados, os mesmos foram classificados de acordo com o gênero, da seguinte forma: Relatos de Pesquisa Empírica, que tratam de pesquisas feitas a partir de dados obtidos por meio de experiências e/ou vivências dos/as pesquisadores/as; Ensaios, que se referem a trabalhos que buscam uma reflexão teórica sobre determinado tema; Levantamento de Área, que concerne a um mapeamento de uma temática 
específica em determinado(s) campo(s) de pesquisa. A distribuição dos trabalhos por gênero está apresentada na Tabela 2.

Tabela 2 - Gênero dos trabalhos

\begin{tabular}{l|c|c}
\hline Gênero & $\begin{array}{c}\text { Número de trabalhos } \\
\text { encontrados }\end{array}$ & Frequência \\
\hline Relatos de Pesquisa Empírica & 4 & $50 \%$ \\
\hline Ensaio & 3 & $37,5 \%$ \\
\hline Levantamento de área & 1 & $12,5 \%$ \\
\hline Total & 8 & $100 \%$ \\
\hline
\end{tabular}

Fonte: elaborada pelas autoras, 2020

Dos quatro trabalhos classificados como Relatos de Pesquisa Empírica, três realizaram estudos em contextos não escolares (privilegiando Unidades de Conservação) e um em contexto escolar. Os três trabalhos classificados como Ensaios refletiram sobre entrelaçamentos teóricos entre o campo da EA e outros campos, tais como da Ecologia Política, da Justiça Ambiental, da Educação do Campo e da Paleontologia, discutindo possibilidades de articulação. No trabalho classificado como Levantamento de Área, os autores fazem referência aos potenciais pedagógicos dos conflitos ambientais, a partir de análises de dados levantados em estudos de Observatórios de Conflitos Ambientais.

Em busca de compreender a ênfase conferida pelos/as autores/as às reflexões desenvolvidas ao longo dos trabalhos selecionados, os mesmos foram, também, compreendidos dentro de quatro categorias, abordadas na continuidade deste trabalho: Contexto Escolar, Formação de Educadores Ambientais, Fundamentação Teórica e Gestão Ambiental. O levantamento da frequência em que os trabalhos ocorrem por categoria segue na Tabela 3.

Tabela 3 - Categorias recorrentes nos trabalhos analisados

\begin{tabular}{l|c|c}
\hline Categoria & $\begin{array}{c}\text { Número de trabalhos encontrados } \\
\text { em cada categoria }\end{array}$ & Frequência \\
\hline Fundamentação Teórica & 3 & $37,5 \%$ \\
\hline $\begin{array}{l}\text { Formação de Educadores } \\
\text { Ambientas }\end{array}$ & 1 & $12,5 \%$ \\
\hline Contexto Escolar & 2 & $25 \%$ \\
\hline Gestão Ambiental & 2 & $25 \%$ \\
\hline Total & 8 & $100 \%$ \\
\hline
\end{tabular}

Fonte: elaborada pelas autoras, 2020

Através da análise temática foi possível organizar os trabalhos, conforme o Quadro 1, o qual permite vislumbrar o anúncio da EP na pesquisa em Educação Ambiental, considerando o corpus delimitado, manifesto nos oito trabalhos investigados por edição e de acordo com cada região, autores/as e/ou grupo de estudos e pesquisas.

\begin{tabular}{|c|c|c|}
\hline ANO & REGIÃO & TÍTULO \\
\hline $\begin{array}{l}2011 \\
(\mathrm{VI} \\
\text { EPEA) }\end{array}$ & $\begin{array}{l}\text { Centro- } \\
\text { oeste/ } \\
\text { Nordeste }\end{array}$ & $\begin{array}{l}\text { Mapeando as macrotendências político-pedagógicas da } \\
\text { educação ambiental contemporânea no Brasil } \\
\text { LAYRARGUES, Philippe Pomier (UnB), LIMA, Gustavo Ferreira da Costa } \\
\text { (UFPB) }\end{array}$ \\
\hline & & Educação Ambiental no licenciamento de petróleo e gás: um estudo sobre a \\
\hline
\end{tabular}




\begin{tabular}{|c|c|c|}
\hline $\begin{array}{l}2013 \\
(\mathrm{VII} \\
\text { EPEA) }\end{array}$ & Sudeste & $\begin{array}{l}\text { implementação de projetos voltados para pescadores artesanais do Recôncavo } \\
\text { Baiano } \\
\text { VASCONCELLOS, Lívia Gomes (UFRJ) }\end{array}$ \\
\hline \multirow{2}{*}{$\begin{array}{l}2015 \\
\text { (VIII } \\
\text { EPEA) }\end{array}$} & Sudeste & $\begin{array}{l}\text { O encontro do cinema com a educação ambiental crítica no Parque Nacional da } \\
\text { Restinga de Jurubatiba } \\
\text { COSTA, Rafael (NUPEM/UFRJ), YU-MING, Juliette (Livre pensadora e } \\
\text { cineasta independente), SÁNCHEZ, Celso (UNIRIO) }\end{array}$ \\
\hline & Sul & $\begin{array}{l}\text { Ecologia Política e territorialidade: contributos à uma introdução dos } \\
\text { fundamentos da Educação Ambiental do Campo } \\
\text { CLARO, Lisiane Costa (PPGEA/FURG), PEREIRA, } \\
\text { Roberta Avila (FURG), PEREIRA, Vilmar Alves (PPGEA/FURG) }\end{array}$ \\
\hline \multirow{3}{*}{$\begin{array}{l}2017 \\
(\mathrm{IX} \\
\text { EPEA) }\end{array}$} & Sudeste & 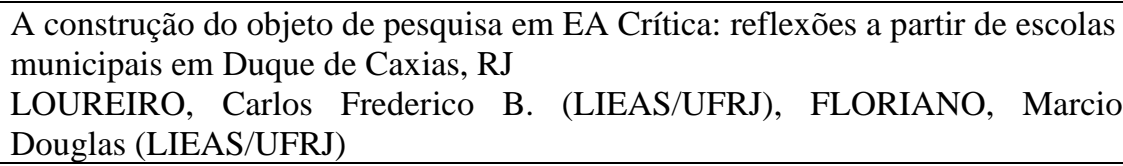 \\
\hline & Sudeste & $\begin{array}{l}\text { Os observatórios de conflitos ambientais como instrumentos pedagógicos para } \\
\text { fortalecer práticas e pesquisas em Educação Ambiental } \\
\text { KASSIADOU, Anne (UNIRIO), SÁNCHEZ, Celso (UNIRIO), RENAUD, } \\
\text { Daniel (UNIRIO) }\end{array}$ \\
\hline & Sudeste & $\begin{array}{l}\text { Considerações sobre o potencial político-pedagógico de Conselhos Gestores de } \\
\text { Unidades de Conservação } \\
\text { COELHO, Breno Herrera da Silva (Instituto Chico Mendes-MMA); } \\
\text { LOUREIRO, Carlos Frederico Bernardo (LIEAS-UFRJ) }\end{array}$ \\
\hline $\begin{array}{l}2019 \\
(\mathrm{X} \\
\text { EPEA) }\end{array}$ & Sudeste & $\begin{array}{l}\text { Paleontologia e Educação Ambiental: possibilidades e desafios para o ensino e } \\
\text { a justiça ambiental } \\
\text { SILVA, Camila Neves (UFJF); COSENZA, Angélica (UFJF). }\end{array}$ \\
\hline
\end{tabular}

Quadro 1 - Relação dos trabalhos filtrados por edição do EPEA, autoria e região

Fonte: elaborado pelas autoras, 2020

De acordo com o quadro acima, os trabalhos filtrados concentram-se, em sua maioria, em grupos de pesquisa da região Sudeste do país, com apenas um dos estudos produzido na região Sul, por pesquisadores da Universidade Federal do Rio Grande (FURG/RS), e outro, agregando região Centro-Oeste à Nordeste, por pesquisadores da Universidade Federal da Paraíba (UFPB) e da Universidade de Brasília (UNB), sendo esse segundo autor, também pesquisador do Laboratório de Investigação em Educação, Ambiente e Sociedade da Universidade Federal do Rio de Janeiro (UFRJ). Todos os outros seis trabalhos partiram, portanto, de grupos de pesquisa da região Sudeste, sendo cinco do estado do Rio de Janeiro (UFRJ e Universidade Federal do Estado do Rio de Janeiro - UNIRIO) e um de Minas Gerais (Universidade Federal de Juiz de Fora - UFJF). Tal dado nos leva a apostar em uma tendência de concentração de discussões e produções nos trabalhos investigados que relacionam os pressupostos teóricos de EP à EA no Sudeste brasileiro, com especial atenção do estado do Rio de Janeiro. Entretanto, devemos considerar o limite de busca deste trabalho, que delimita somente o evento EPEA, assim como o corpus utilizado (procedente dos campos de busca).

Quanto às categorias, construídas na leitura e análise dos trabalhos, percebemos que as discussões que as consubstanciam apontam para uma busca dos/as autores/as em anunciar novas contribuições teóricas e/ou práticas ao campo da EA. Também, foi possível observar certa convergência entre os campos quanto a autores utilizados, sendo os mais referenciados: Boaventura de Sousa Santos, Carlos Walter Porto-Gonçalves, Enrique Leff, Guillermo Foladori, Héctor Alimonda e Henri Acselrad, com alguns trabalhos fazendo referência a uma maior diversidade de autores do campo da EP do que outros.

Iniciamos nossa análise a partir da categoria Fundamentação Teórica, categoria esta que apresentou três trabalhos fazendo referência à Ecologia Política, um no ano de 2011, ano em que o termo Ecologia Política apareceu, pela primeira vez, nos campos de busca delimitados, um em 2017, e outro no ano 2019, referente à última edição do EPEA. 
Nessa categoria, no trabalho Mapeando as macrotendências político-pedagógicas da Educação Ambiental contemporânea no Brasil, de Layrargues e Lima (2011), os autores elucidam as diferentes vertentes do campo da EA no país, dialogando com a literatura específica da área a partir de referenciais da Ecologia Política e da noção de Campo Social de Pierre Bourdieu. A Ecologia Política aparece como uma contribuição das ciências humanas e sociais para a reflexão e o debate ecológico, uma vez que tal campo potencializa, segundo os autores, uma compreensão político-ideológica dos mecanismos de reprodução social em sua interface com a natureza. A esse respeito, Leff (2013, p. 14) discute a emergência do termo Ecologia Política, desde a sua primeira aparição na literatura acadêmica, assinalando que "a ecologia política surgiu como uma resposta social ao esquecimento da natureza pela economia política".

O segundo trabalho agregado a essa categoria, intitulado Os Observatórios de conflitos ambientais como instrumentos pedagógicos para fortalecer práticas e pesquisas em Educação Ambiental, foi apresentado no IX EPEA. No desenvolvimento do mesmo, Kassiadou, Sánchez e Reunaud (2017) propõem uma discussão dos pressupostos de uma EA que se pretende crítica, por meio de dados obtidos em estudos de trabalhos contidos em Observatórios de Conflitos Ambientais. As análises foram subsidiadas pelas categorias conceituais freireanas, tais como situação-limite, ato-limite e inédito-viável (FREIRE, 2014). No trabalho, os autores dão destaque às pesquisas e práticas no contexto latino-americano, utilizando-se de autores como Acselrad (2004); Martinez-Alier (2015); e Loureiro e Layrargues (2013).

A EP é referenciada no trabalho como um possível campo de diálogo para aqueles que buscam compreender e elucidar as dimensões pedagógicas dos conflitos ambientais, uma vez que, segundo Kassiadou, Sánchez e Reunaud (2017), esse diálogo contribui para a compreensão das assimetrias e desigualdades ambientais, ao enunciar as disputas políticas, legitimar os enfrentamentos aos conflitos ambientais e anunciar outras epistemologias e pedagogias de base popular.

De maneira semelhante, no trabalho apresentado no X EPEA, intitulado Paleontologia e Educação Ambiental: possibilidades e desafios para o ensino e a justiça ambiental, Silva e Cosenza (2019) buscam um olhar para a Paleontologia que ultrapasse seus limites etimológicos, a partir de contribuições dos campos da EP e da EA. Segundo as autoras, tais campos ajudam a pensar em como a ciência dos fósseis se relaciona às discussões sobre desigualdades ambientais, uma vez que os sítios paleontológicos podem ser locais de conflitos ambientais advindos do turismo e da mineração. Nesse sentido, as autoras ressaltam que, no contexto da atual crise ambiental, é importante situar a Paleontologia junto a outros campos, como a EP e a EA, em busca de dar visibilidade ao quadro de conflitos e vulnerabilidades ambientais, aliando a conservação da natureza ao reconhecimento da realidade local, ao direito das comunidades e ao direito ao território.

Na segunda categoria, Formação de Educadores Ambientais, o trabalho $O$ encontro do cinema com a educação ambiental crítica no Parque Nacional da Restinga de Jurubatiba, de autoria de Costa, Yu-ming e Sánchez (2015), busca evidenciar uma reflexão sobre as questões ambientais a partir da realidade de conflitos existentes no Parque Nacional da Restinga de Jurubatiba (RJ), utilizando-se da prática cinematográfica como ferramenta educativa na perspectiva da problematização da realidade. O trabalho partiu de um caso empírico, vivenciado pelos autores, que permitiu a aproximação entre o cinema e a Educação Ambiental Crítica, com a produção de nove documentários, analisados e discutidos de modo a promover o diálogo com atores locais e a reflexão sobre os conflitos ambientais. Com o aporte da EP e da perspectiva educativa freireana, foram conduzidos cursos de formação, denominados Curso de Cinema Ambiental, de modo a suscitar o debate acerca das relações de poder inerentes às questões ambientais locais. Ao longo do trabalho, os autores tecem uma 
discussão em torno das produções cinematográficas desenvolvidas no que tange à relação entre os valores e conceitos retratados com as diferentes concepções de Educação Ambiental.

Dessa maneira, os autores propõem diálogos com campo da Ecologia Política no intuito de contrapor as pedagogias que afirmam e reproduzem a lógica hegemônica, dando visibilidade a processos educativos em espaços não formais, a pedagogias outras, que resistem e insurgem em contexto de desigualdades socioambientais. Novamente, a temática do conflito ambiental surge, constituindo um lugar de enunciação forte na relação EA e EP. Nessa perspectiva, Walsh $(2017$, p. 36) destaca que, na construção de um processo educativo contrahegemônico, a pedagogia deve ser compreendida "como una práctica y un proceso sociopolítico productivo, como una metodología esencial e indispensable, fundamentada en la realidad de las personas, sus subjetividades, historias y luchas, como decía Freire (1974)".

No que tange aos processos educativos estabelecidos em espaços formais de ensino, dois trabalhos foram compreendidos na terceira categoria, Contexto Escolar. No primeiro trabalho, intitulado Ecologia Política e territorialidade: contributos a uma introdução dos fundamentos da Educação Ambiental do Campo, Claro, Pereira e Pereira (2015) fazem uma discussão sobre a educação escolar no campo, a partir do contexto histórico brasileiro, o qual é marcado por processos de injustiças e conflitos ambientais territoriais rurais. Nesse sentido, discutem a potencialidade de uma EA que se faça crítica na compreensão sobre o ambiente, bem como sobre as contradições ambientais, e refletem sobre a constituição de uma Educação Ambiental do Campo. Para tanto, tecem aproximações entre os conceitos de Ecologia Política e de territorialidade, pelo fato de ambos contribuírem na compreensão das concepções existentes sobre o campo e sobre processos de injustiças ambientais e violações de direitos velados pela promessa do desenvolvimento, uma vez que os povos do campo concebem seus meios de produção e suas pedagogias no território. No trabalho, o termo território é reportado ao conceito de territorialidade, segundo Little (2002 apud CLARO; PEREIRA; PEREIRA, 2015, p. 12), referindo-se ao "esforço coletivo de um grupo social para ocupar, usar, controlar e se identificar com uma parcela específica de seu ambiente biofísico, convertendo-a, assim, em seu 'território' ou 'homeland"'.

$\mathrm{Na}$ perspectiva de construir práticas educativas em conformidade com a realidade ambiental local, Loureiro e Floriano (2017), no trabalho A construção do objeto de pesquisa em EA Crítica: reflexões a partir de escolas municipais em Duque de Caxias, RJ, propõem uma análise da prática de professores, em catorze escolas afetadas pelo Polo Industrial de Duque de Caxias (refinaria), a partir de levantamentos de conflitos socioambientais locais e entrevistas com professores e responsáveis. No trabalho, os autores refletem sobre os limites das propostas educativas estabelecidas nas escolas, as quais engessam o potencial de reflexão e discussão, e invisibilizam questões locais, assim como analisam as proposições para compreensão e enfrentamento das mesmas, como as ações estabelecidas pelos movimentos locais. Nesse contexto, os autores destacam que construir um objeto de pesquisa em Educação Ambiental Crítica requer uma fundamentação teórica para compreensão das contradições e disputas, e participação coletiva e organizada das comunidades que compõem o contexto local, elementos, estes, que, segundo os autores, são abordados no campo da Ecologia Política.

Em ambos os trabalhos da categoria Contexto Escolar notamos a forte presença da perspectiva da Justiça Ambiental, com grande ênfase às questões locais, territoriais. Ainda que os problemas socioambientais se façam presentes nas áreas onde se localizam as escolas, os autores dos dois trabalhos discutem a necessidade e a dificuldade em construir uma prática educativa com potencial problematizador da realidade local, tanto por questões relativas às próprias escolas, quanto pelas relações estabelecidas a partir de discursos dos diferentes sujeitos sociais envolvidos no processo. Nesse contexto, Cosenza, Kassiadou, Sánchez (2014, p. 40) refletem sobre a potencialidade dos espaços formais de ensino na produção de práticas 
educativas emancipatórias, ao pensarmos "a escola básica como um lócus privilegiado de experiências de participação, reflexão e prática das relações entre indivíduos-coletividades, afirmação de identidades e diferenças e valorização de culturas".

Em relação à quarta categoria, Gestão Ambiental, os trabalhos selecionados discutem como as políticas públicas, assim como a Educação em processos de Gestão, podem envolver relações assimétricas entre planejadores e beneficiários das ações. Vasconcellos (2013), no trabalho intitulado Educação Ambiental no licenciamento de petróleo e gás: um estudo sobre a implementação de projetos voltados para pescadores artesanais do Recôncavo Baiano, a partir de um estudo de caso, recorre a autores da EP para compreender a relação dos conflitos ambientais com expressões do modo de produção capitalista, como a disputa por sentidos na apropriação e uso dos territórios. Nessa perspectiva, a autora atenta para o uso do termo comunidade em diferentes discursos, pelo fato do seu significado ser diverso. No caso, os sujeitos envolvidos não se autodenominavam comunidade. A participação popular é compreendida como elemento essencial para a superação das relações de opressão, uma vez que os sujeitos, historicamente excluídos das decisões políticas, têm nos projetos de Educação Ambiental (ligados à Gestão Ambiental) um espaço de construção do conhecimento e uma possibilidade de emancipação.

Do mesmo modo, Coelho e Loureiro (2017), no trabalho Considerações sobre o potencial político-pedagógico de conselhos gestores de unidades de conservação, também localizado por nós dentro da categoria Gestão Ambiental, discutem os potenciais políticopedagógicos que poderiam ser desenvolvidos nos conselhos de Unidades de Conservação, por meio da análise de resultados de um estudo de caso no processo de Licenciamento do Complexo Petroquímico do Rio de Janeiro. Autores referenciados pelo campo da EP, como Boaventura de Sousa Santos, são citados no trabalho, ao discutirem as implicações do sistema capitalista no potencial político-pedagógico dos conselhos gestores. Os trabalhos dessa categoria trazem à tona relações político-pedagógicas envolvidas em processos de Gestão Ambiental, reconhecendo os limites e as potencialidades de tais processos, uma vez que a Gestão Ambiental tem um importante papel na garantia da participação popular, embora as amarras institucionais possam contribuir com a legitimação do sistema hegemônico.

A julgar pela análise das categorias, os autores elucidaram aspectos fundamentais para a construção de processos educativos em EA que se pretendam contra-hegemônicos, sendo os trabalhos investigados como locais de anúncio de educabilidades outras, seja na perspectiva da fundamentação teórica e/ou no estabelecimento de práticas, em espaços formais e não formais de ensino.

Segundo Layrargues e Lima (2011), no campo da EA os trabalhos que se colocam em diálogo com o campo da Ecologia Política e afins apresentam um viés sociológico e político bem demarcado, e, portanto, empregam alguns conceitos-chave em suas discussões sobre as questões ambientais, como Cidadania, Democracia, Participação, Emancipação, Conflito, Justiça Ambiental e Transformação Social. Nesse sentido, durante a constituição das categorias investigadas, reconhecemos que os trabalhos versavam, majoritariamente, sobre as temáticas Conflito, Participação e Território, o que nos levou a aprofundar o olhar para o modo como apareciam nos trabalhos investigados.

$\mathrm{Na}$ EA os conflitos ambientais são compreendidos como espaços de participação popular no território, de enfrentamento de diferentes cosmovisões ambientais e de vida, assim como de produção de educabilidade, ao nos possibilitarem compreender os sentidos e significados atribuídos ao ambiente, bem como as relações de força e poder que agem sobre os territórios e seus sujeitos (COSENZA; KASSIADOU; SÁNCHEZ, 2014).

Nessa perspectiva, todos os oito trabalhos filtrados abordaram a temática conflito, sendo que em alguns a mesma teve um maior enfoque. Na busca por construir uma Educação Ambiental do Campo, Claro, Pereira e Pereira (2015, p. 2) reconhecem que no contexto do 
campo brasileiro "o eixo estrutural desses conflitos ocorre a partir da disputa pela terra, enquanto o direito que apresenta ao ser utilizada para o sustento das comunidades". Segundo os/as autores/as, os conflitos no campo, em sua maioria, se tratam de conflitos territoriais, portanto, a temática território é, também, destacada no estudo, com ênfase no aspecto da territorialidade, que "assume a contextualização dos diversos povos e as relações sociais e naturais em correspondência ao território constituído" (CLARO; PEREIRA; PEREIRA, 2015, p. 14). Ainda, a temática participação é levantada no estudo, no que tange à importância de ampliar os espaços políticos, em busca de uma participação mais efetiva dos trabalhadores/as para além de suas comunidades.

Coelho e Loureiro (2017) abordam os conflitos de interesse em torno do ambiente no que tange o estabelecimento de Unidades de Conservação. Fazendo referência ao termo território, tais autores enfatizam a forte relação entre as populações tradicionais e seus territórios que, por serem constitutivos de seus modos de vida, demandam proteção frente às ameaças. No estudo, a temática participação é vinculada à dimensão pedagógica, ao relacionar a possibilidade de acesso a informações a partir da participação direta dos atores locais na gestão das UCs, e, também, para expor as assimetrias de poder diante da suposta igualdade de participação dos conselheiros nas tomadas de decisão.

Essa forte relação entre a população local e o território em áreas protegidas também é referenciada no trabalho de Costa, Yu-ming e Sánchez (2015), ao reportarem aos conflitos em torno de uma UC, o Parque Nacional, e no trabalho de Silva e Cosenza (2019), no qual as autoras destacam as vulnerabilidades socioambientais de sítios paleontológicos.

Ao discutirem o potencial pedagógico dos observatórios de conflitos ambientais Kassiadou, Sánchez e Reunaud (2017) destacam a importância de compreendermos e utilizarmos determinados conceitos, como território, na busca por compreender as relações de poder em torno da questão ambiental, e anunciar epistemologias e pedagogias outras. A temática participação não é amplamente discutida no estudo, sendo utilizada para indicar a sua importância na esfera pública das políticas ambientais e nas lutas e enfrentamento aos conflitos.

Ao encontro dessa visão sobre a participação, Loureiro e Floriano (2017) dão maior destaque à temática participação, identificando a participação do entorno da Refinaria Duque de Caxias (REDUC) como coletiva e organizada das comunidades, com articulação de órgãos e instituições como o sindicato e a secretaria municipal de educação. A temática território é referenciada, pontualmente, no estudo para especificar o tipo de conflito em questão, o qual se relaciona ao uso e apropriação do território.

Partindo de uma abordagem dos aspectos legais, como a constituição Federal, Vasconcellos (2013), reporta ao direito da participação da sociedade na proteção do meio ambiente, e discute a efetivação dessa participação, principalmente daqueles/as historicamente excluídos dos processos de decisão política, tendo em vista que, muitas vezes, os espaços de participação contribuem para a manutenção da dominação. A temática território é referenciada no estudo para a caracterização conceitual de conflitos de acordo com definição de Acselrad (2004 apud VASCONCELLOS, 2013, p.3) que concebe que um "conflito ambiental ocorre no âmbito das práticas espaciais materiais", a partir da introdução de práticas que interferem, de forma negativa, às já existentes em um determinado território, sendo destacada a necessidade de analisar a apropriação material e simbólica, que se relaciona às distintas formas de "apropriação, uso e significação do território" (ACSELRAD, 2004 apud VASCONCELLOS, 2013, p.3).

Diante das análises explicitadas, reconhecemos uma interseção entre as temáticas Conflito, Participação e Território ao longo dos trabalhos, em decorrência das mesmas se interrelacionarem na constituição dos pressupostos que são centrais para a Ecologia Política, os quais buscam compreender como os diferentes atores sociais "disputam e compartilham 
recursos naturais e ambientais e em qual contexto ecológico tais relações se estabelecem". (LOUREIRO; LAYRARGUES, 2013, p. 56). Dessa forma, o campo da EP lança à EA possibilidades de apreender e relacionar conceitos-chave que permeiam a questão ambiental, em diálogo com perspectivas e paradigmas educativos que objetivem uma transformação social, frente àquelas estabelecidas pelo sistema capitalista, o que expõe a contínua "disputa discursiva, teórica e política pela hegemonia do campo", conforme nos apontam Layrargues e Lima (2011, p. 12).

Assim, inspiradas por Walsh (2017) que traz os gritos, as gretas e as sementes de uma pedagogia decolonial, ao anunciar processos, estratégias e práticas insurgentes de resistir, (re)existir e (re)viver, enxergamos esse levantamento, em anais das edições do EPEA, ainda que dentro do limite do corpus delimitado, como sendo um importante esforço na busca por compreender como a Ecologia Política pode contribuir com o campo da EA no estabelecimento de processos educativos que estejam comprometidos com construção de uma sociedade socioambientalmente justa.

\section{Considerações Finais}

O momento exige que repensemos o nosso modelo de sociedade. Em meio a uma eminente catástrofe (ou catástrofes), nos deparamos com potenciais conhecimentos e oportunidades para pensar caminhos alternativos urgentes e necessários.

Nesse sentido, acreditamos que o campo da Ecologia Política, ao apontar limites do processo civilizatório na apropriação da natureza, que são determinantes para a crise ambiental, bem como para o estabelecimento de relações de poder, possibilita outros olhares sobre as questões ambientais, potencializando uma transformação social em diversas dimensões, sejam elas epistemológicas, políticas, econômicas, sociais, culturais, pedagógicas.

A partir de uma releitura da ciência ecológica tradicional, tal campo propõe a construção de outra racionalidade socioambiental, estabelecendo uma crítica à racionalidade moderna-colonizadora, que é responsável pela marginalização e exterminação de determinadas populações ao naturalizar desigualdades socioambientais e situações de vulnerabilidade socioambiental. Nessa perspectiva, o olhar para opressões e as violações de direitos, para além de anunciar que crimes ambientais têm relação com determinados territórios e sujeitos, também anuncia outras formas de resistir, (re)existir e (re)viver. Dessa maneira, o campo da Ecologia Política se faz um importante campo de diálogo para uma Educação Ambiental que pretenda construir processos educativos a partir de uma lógica que se opõe à lógica do sistema capitalista, e, assim, contribuir para o processo de transformação do que é injusto.

Por meio das análises, acreditamos que tal importância se faz notória no campo da EA. Embora tenha havido uma baixa presença/frequência da referência ao campo da EP nos trabalhos em EA, consideramos que há um crescimento geral, e uma tendência futura, contínua, dessa relação, ainda que possamos considerar o limite deste trabalho ao, por exemplo, não incluir estudos que fazem referência à EP no corpo do texto, ou ainda, outros periódicos e eventos. As categorias discutidas, bem como as temáticas identificadas, quais sejam Conflito, Participação e Território, podem ser compreendidas como chaves de leitura para convergências na relação entre EA-EP, permitindo-nos pensar práticas sociais como estratégicas para o debate e o enfrentamento da conjuntura política, em que paira um negacionismo da ciência e uma invisibilização das questões ambientais agudas, envoltas na pandemia, na emergência climática e nos conflitos socioambientais.

Assim, reconhecemos que os entrelaçamentos entre os campos da EA e da EP são fundamentais na apreensão de outros olhares sobre o ambiente e a sociedade, por anunciarem epistemologias e pedagogias insurgentes que são negadas pelo sistema hegemônico, como as 
que emergem da prática social dos sujeitos em situação de vulnerabilidade e dos movimentos sociais em ação nos territórios, e que potencializam a construção de outro modelo de sociedade.

\section{Referências}

ACSELRAD, H. Justiça ambiental: ação coletiva e estratégias argumentativas. In: ACSELRAD, H., et al. (Ed.). Justiça ambiental e cidadania. 2 ed. Rio de Janeiro: Relume Dumará/Fundação Ford, 2004, p.23-37.

ALIMONDA, H. En clave de sur: la Ecología Política Latinoamericana y el pensamiento crítico. In: ALIMONDA, H. et al. (Orgs.). Ecología política latinoamericana: pensamiento crítico, diferencia latinoamericana y rearticulación epistémica. Ciudad Autónoma de Buenos Aires: Ciccus, 2017, p. 3349.

ALIMONDA, H. Ecología política latinoamericana y pensamiento crítico: vanguardias arraigadas. Rev. Desenvolv. Meio Ambiente, Curitiba-PR, v. 35, n.1, p. 161-168, dez. 2015.

ANGELI, T. Significados sobre Justiça Ambiental nas Pesquisas em Educação Ambiental: uma análise a partir de teses e dissertações brasileiras. Inserir ano depósito. . nf.112. Dissertação (Mestrado em Educação) - Universidade Estadual Paulista "Júlio de Mesquita Filho, Rio Claro, 2017.

BARDIN, L. Análise de Conteúdo. São Paulo: Edições 70, 2011.

BIHR, A. França: pela socialização do aparato de saúde. In: DAVIS, M. et al. (Orgs.) Coronavírus e a luta de classes. Terra sem Amos: Brasil, 2020, p. 25-30.

CLARO, C. L.; PEREIRA, R. A.; PEREIRA, V.A. Ecologia Política e Territorialidade: contributos à uma introdução dos fundamentos da Educação Ambiental do Campo. In: ENCONTRO DE PESQUISA EM EDUCAÇÃO AMBIENTAL, 8, 2015, Rio de Janeiro. Anais... Rio de Janeiro, RJ: CAPES, UFRJ, UFRRJ, UNIRIO, FFCLRP, 2015, [s.p.]. Disponível em: <http://epea.tmp.br/epea2015_anais/pdfs/plenary/227.pdf>

COELHO, B.H.S.; LOUREIRO, C.F.B. Considerações sobre o potencial político-pedagógico de conselhos gestores de unidades de conservação. In: ENCONTRO DE PESQUISA EM EDUCAÇÃO AMBIENTAL, 9, 2017, Juiz de Fora. Anais... Universidade Federal de Juiz de Fora, Juiz de Fora, MG: UFJF, UFF, FFCLRP/USP, SP, 2017, [s.p.]. Disponível em: < http://epea.tmp.br/epea2017_anais/pdfs/plenary/0048.pdf>

COSENZA, A.; KASSIADOU, A.; SÁNCHEZ, C. Educação Ambiental e Direitos Humanos: necessárias articulações a partir da justiça ambiental e da ecologia política. In: SILVA, A.M.M.S.; TIRIBA, L. (Orgs.). Direito ao Ambiente como Direito à Vida: desafios para a educação em direitos humanos. São Paulo: Cortez, 2014, p. 21-26.

COSTA, R.N.; YU-MING, J.; SÁNCHEZ, C. O encontro do cinema com a educação ambiental crítica no parque nacional da restinga de Jurubatiba. In: ENCONTRO DE PESQUISA EM EDUCAÇÃO AMBIENTAL, 8, 2015, Rio de Janeiro. Anais... Rio de Janeiro, RJ: CAPES, UFRJ, UFRRJ, UNIRIO, FFCLRP, 2015, [s.p.]. Disponível em: < http://epea.tmp.br/epea2015_anais/pdfs/plenary/148.pdf>

DAVIS, M. A crise do coronavírus é um monstro alimentado pelo capitalismo. In: DAVIS, M. et al. (Orgs) Coronavírus e a luta de classes. Brasil: Terra sem Amos, 2020, p. 5-12.

FREIRE, P. Pedagogia do oprimido. 57 ed. Rio de Janeiro: Paz e Terra, 2014. 
FOLADORI, G. O capitalismo e a crise ambiental. Revista Raízes, Campina Grande, Ano XVIII, [s.v], n. 19, p. 31-36, 1999.

FOLADORI, G. Bases marxistas para la educación ambiental. Revista Ambiente \& Educação, Rio Grande, v. 23, n. 3, p. 159-169, 2018.

HARVEY, D. Política anticapitalista em tempos de COVID-19. In: DAVIS, M. et al. (Orgs)

Coronavírus e a luta de classes. Brasil: Terra sem Amos, 2020, p. 13-23.

KASSIADOU, A; SÁNCHEZ, C. Ecologia política na educação ambiental e as potencialidades pedagógicas dos conflitos ambientais. Revista Sergipana de Educação Ambiental, São Cristóvão, v. 8, n.2, p. 09-25, 2019.

KASSIADOU, A.; SÁNCHEZ, C; REUNAUD, D. Os observatórios de conflitos ambientais como instrumentos pedagógicos para fortalecer práticas e pesquisas em educação ambiental. In:

ENCONTRO DE PESQUISA EM EDUCAÇÃO AMBIENTAL, 9, 2017, Juiz de Fora. Anais... Universidade Federal de Juiz de Fora, Juiz de Fora, MG: UFJF, UFF, FFCLRP/USP, SP, 2017, [s.p.]. Disponível em: 〈http://epea.tmp.br/epea2017_anais/pdfs/plenary/0060.pdf>

LAYRARGUES, P.P.; LIMA, G. Mapeando as Macrotendências político-pedagógicas da Educação Ambiental no Brasil. In: ENCONTRO DE PESQUISA EM EDUCAÇÃO AMBIENTAL, 6, 2011, Ribeirão Preto. Anais... Universidade de São Paulo, Ribeirão Preto, SP: USP/RP, UNESP/Rio Claro, UFSCar, UNESP/Rio Claro, 2011, [s.p.]. Disponível em: <

http://www.epea.tmp.br/viepea/epea2011_anais/trabalhos-aprovados/index.html>

LEFEBVRE, H. A revolução Urbana. Belo Horizonte: UFMG, 1999.

LEFF, E. Ecologia, Capital e Cultura: a territorialização da racionalidade ambiental. Petrópolis: Vozes, 2009.

LEFF, E. Ecologia Política: uma perceptiva latino-americana. Revista Desenvolvimento e Meio Ambiente, Curitiba, v. 27, n.1, p.11-20, 2013.

LEFF, E. A aposta pela vida: imaginação sociológica e imaginários sociais nos territórios ambientais do Sul. Petrópolis: Vozes, 2018.

LOUREIRO, C.F.B.; FLORIANO, M.D. A construção do objeto de pesquisa em EA crítica: reflexões a partir de escolas municipais em Duque de Caxias, RJ. In: ENCONTRO DE PESQUISA EM EDUCAÇÃO AMBIENTAL, 9, 2017, Juiz de Fora. Anais... Universidade Federal de Juiz de Fora, Juiz de Fora, MG: UFJF, UFF, FFCLRP/USP, SP, 2017, [s.p.]. Disponível em:

<http://epea.tmp.br/epea2017_anais/pdfs/plenary/0052.pdf>

LOUREIRO, C.F.B; LAYRARGUES, P,P. Ecologia Política, Justiça e Educação ambiental Crítica: perspectivas de aliança contra-hegemônica. Rev. Trab. Educ. Saúde, Rio de Janeiro, v.11, n.1, p.53-71, 2013.

MALDONADO-TORRES, N. "Sobre la colonialidad del ser: contribuciones al desarrollo de un concepto". En: Santiago Castro-Gómez y Ramón Grosfoguel (Eds.). El giro decolonial. Reflexiones para una diversidad epistémica más allá del capitalismo global. Bogotá: Iesco-Pensar-Siglo del Hombre Editores, 2007, p. 127-167.

MARTÍNEZ- ALIER, J. M. O ecologismo dos pobres: conflitos ambientais e linguagens de valoração. 2.ed. São Paulo: Contexto, 2015. 
OBSERVATÓRIO DA EDUCAÇÃO AMBIENTAL - OBSERVARE 2020. Disponível em: https://observatorioea.blogspot.com/p/nos-educadores-e-educadoras-ambientais.html. Acesso em: 09 jun. 2021.

PALACIO, G.; VARGAS, A.; HENNESSY, E. Antropoceno o Capitaloceno en fricción. DesEncuentros entre Geociencias e Historia. In: ALIMONDA, H.; PÉREZ, C.T.; MARTÍN, F. (Coords.). Ecologia política latinoamericana: pensamento crítico, diferencia latino-americana y rearticulación epistémica. v. 2. Ciudad Autónoma de Buenos Aires: Ciccus, 2017, p. 265-288.

PORTO-GONÇALVES, C.W. A dimensão geopolítica da crise brasileira: uma perspectiva desde os grupos sociais em situação de subalternização. GEOgraphia, Niterói-RJ, Ano18, [s.v], n. 37, p.9-34, 2016.

QUIJANO, A. Colonialidad del Poder y Clasificacion Social. Festchrift for Immanuel Wallerstein Part I. Jornal of world-systems research, Buenos Aires, v.6, Special Issue, p. 342-386, 2000.

QUIJANO, A. Colonialidad del Poder, Eurocentrismo y América Latina. In LANDER, E. (Org.) La Colonialidad del Saber - eurocentrismo y ciencias sociales - perspectivas latinoamericanas. Buenos Aires: Clacso/Unesco, 2005, p. 117-142.

SANTOS, B.S. Conocer desde el Sur: para una cultura política emancipatória. Lima: UNMSM, 2006.

SANTOS, B.S. A Cruel Pedagogia do Vírus. Coimbra: Almedina, 2020.

SANTOS, B.S; MENEZES, M.P. (Orgs.). Epistemologias do Sul. São Paulo: Cortez, 2009.

SILVA, C.N.; COSENZA, A. Paleontologia e Educação Ambiental: Possibilidades e desafios para o ensino e a justiça ambiental. In: ENCONTRO PESQUISA EM EDUCAÇÃO AMBIENTAL EPEA, 10, 2019, São Cristóvão.

Anais... Universidade Federal de Sergipe, São Cristóvão, SE: UFJF, MG; UFF, RJ; FFCLRP/USP, SP, 2019, [s.p.]. Disponível em: < http://epea.tmp.br/epea2019_anais/pdfs/plenary/0196-1-B-01.pdf>

SILVA, M.A. COSENZA, A. PINTO, V.P.S. Justiça, racismo e conflitos ambientais na literatura sobre educação ambiental: o que dizem os anais dos Encontros Nacionais de Pesquisa em Educação Ambiental? In: ENCONTRO DE PESQUISA EM EDUCAÇÃO AMBIENTAL, 9, 2017, Juiz de Fora. Anais... Universidade Federal de Juiz de Fora, Juiz de Fora, MG: UFJF, UFF,FFCLRP/USP, SP, 2017, [s.p.]. Disponível em: < http://epea.tmp.br/epea2017_anais/welcome/>

VASCONCELLOS, L.G. Educação Ambiental no licenciamento de petróleo e gás: um estudosobre a implementação de projetos voltados para pescadores artesanais do recôncavo baiano. In: ENCONTRO DE PESQUISA EM EDUCAÇÃO AMBIENTAL, 7, 2013, Rio Claro. Anais... UNESP/Rio Claro, Rio Claro, SP: IB-Rio Claro - UNESP / FFCLRP-USP / UFSCar / IB-Botucatu - UNESP, 2013, [s.p.]. Disponível em: <http://www.epea.tmp.br/epea2013_anais/committees/>

WALSH, C. (Ed.). Pedagogías decoloniales: prácticas insurgentes de resistir, (re)existir y (re)vivir. Tomo II. Quito: Ediciones Abya-Yala, 2017. 